\title{
Assessment of Prophylactic Effect of Atropine with Ephedrine in Prevention of Hypotension Induced by Spinal Anaesthesia in Elderly Patients: A Comparative Study
}

\author{
Sanjay Jain ${ }^{1^{*}}$, Atul Kaushik ${ }^{2}$ \\ ${ }^{1 *}$ Assistant professor, Department of Anesthesiology, \\ Rama Medical College Hospital \& Research Centre, Hapur, Uttar Pradesh, India. \\ ${ }^{2}$ Assistant professor, Department of Anesthesiology, \\ School of Medical Sciences and Research, Sharda University, Greater Noida, Uttar Pradesh, India.
}

\begin{abstract}
Background: Hypotension is one of the major adverse effects seen in patients undergoing spinal anaesthesia and is reported to be seen in more than 30 percent of the cases of patients receiving spinal anaesthesia. It has been highlighted in various studies that the use of atropine and ephedrine in the improvement of hemodynamic parameter when used preoperatively in spinal aesthesia. Hence; we carried this study to evaluate and compare the heart rate and mean arterial pressure after spinal anaesthesia with prophylactic use of atropine, ephedrine and placebo in elderly patients.

Materials \& Methods: The present study was conducted among 120 patients who underwent surgical procedures under spinal anaesthesia. Patients were randomly divided into three study groups; Group 1 (40 patients): who received normal saline, Group 2 (40 patients) who received $0.6 \mathrm{mg}$ of atropine and Group 3 (40 patients) who received $12 \mathrm{mg}$ of ephedrine. Study drugs were administered to the patients one minute after the spinal anaesthesia. Recording of the various parameters such as amount of vasopressor needed (phenlyephrine), after 15 minutes of spinal anaesthesia, sensory level reached presence of intra-operative angina and intra/postoperative confusion and other side effects till six hours post-surgically was done. All the results were analyzed by SPSS software.

Results: MAP at the baseline time in the three study groups was found to be $98.5,91.5$ and 93.7 respectively. 14 patients in
\end{abstract}

\section{INTRODUCTION}

Spinal anaesthesia is being used as a routine procedure for carrying out various surgical procedures since long time. After the insertion of the needle in the plane of neuraxis, sympathetic block, sensory analgesia and motor block, depending on dose, concentration, or volumes of local anaesthetics are produced by this procedure. One of the major disadvantages of the spinal block is the precipitous hypotension. Hypotension is reported to be seen in more than 30 percent of the cases of patients receiving spinal anesthesia.1,2 Hypotension occurring after spinal blockage is further precipitated by the absence of significant amount of reflex tachycardia. Blockade of cardio accelerator sympathetic fibers at T1 to T4, and possibly the "reverse" of the Bainbridge reflex are further responsible for occurrence of these phenomenons. One of the prominent mechanisms producing hypotension is the the group 3 were observed to have bradycardia while none of the patients in group 1 and group 2 suffered from bradycardia at baseline. Significant results were obtained while comparing the mephentemine used and amount of patients affected by bradycardia when compared in between the various study groups.

Conclusion: It can be concluded that profile of atropine is better as compared to ephedrine in the maintenance of hemodynamic in elderly patients.

Key Words: Anaesthesia, Hypotension, Spinal.

\section{*Correspondence to}

Dr Sanjay Jain,

Assistant professor, Department of Anesthesiology,

Rama Medical College Hospital \& Research Centre, Hapur, Uttar Pradesh, India.

\section{Article History}

Received: 22-06-2016, Revised: 12-07-2016, Accepted: 29-07-2016

\begin{tabular}{|l|c|}
\hline \multicolumn{2}{|c|}{ Access this article online } \\
\hline Website: & Quick Response code \\
www.ijmrp.com & \\
\hline DOI: & \\
10.21276/ijmrp.2016.2.4.042 & \\
\hline
\end{tabular}

sympathetic blockage leading to the systemic vasodialation after the administration of spinal anaesthesia. One of the current topics of research is the search such of a technique or combinations to prevent spinal anaesthesia induced hypotension and bradycardia. ${ }^{3,4}$ Various studies have highlighted the use of atropine and ephedrine in the improvement of hemodynamic parameter when used preoperatively in spinal aesthesia. ${ }^{5,6}$ Hence; we carried this study to evaluate and compare the heart rate and mean arterial pressure after spinal anaesthesia with prophylactic use of atropine, ephedrine and placebo in elderly patients.

\section{MATERIALS \& METHODS}

The present study was conducted in the department of medicine and anaesthesiology of the institution and included prospective 
assessment of 120 patients who underwent surgical procedures under spinal anaesthesia. Ethical approval was taken from the institutional ethical committee in written and consent was obtained from all the patients after explaining them the entire research protocol.

Elderly patients of equal to or more than 60 years of age, who were scheduled to undergo urological surgeries under spinal anaesthesia and patients with physical status (ASA PS) I-II according to American Society of Anaesthesiologist were included in the study. Exclusion criteria for the present study included uncooperative patients, patients in which spinal anaesthesia was contraindicated, patients having history of cardiac arrhythmia such as atrial fibrillation, patients with history of first degree heart blocks, hypertensive patients having systolic or diastolic blood pressure more than $140 \mathrm{~mm}$ or $100 \mathrm{~mm}$ of $\mathrm{Hg}$, patients having unstable angina, patients suffering from cardiomyopathy, patients on $\beta$-adrenergic blockers and patients taking any drug which is known to alter the effect of study drugs.

Pre-anaesthetic evaluations were carried out in all the patients and after evaluation, were randomly divided into three study groups; Group 1: who received normal saline, Group 2: who received $0.6 \mathrm{mg}$ of atropine and Group 3: who received $12 \mathrm{mg}$ of ephedrine. Final volume concentration of all the drugs in the study groups was achieved to $2.5 \mathrm{ml}$. One minute after the induction of the spinal anaesthesia in the patients of all the three study groups, their allotted drugs were administered. Before the commencement of the surgery, all the patients were given pre-medication in the form of tab midazolam orally. Preloading of all the patients with normal saline (NS) was done in the preanesthetic preparation room, before the induction of spinal anaesthesia. Monitoring of all the patients in operating room was done or recording the values of baseline heart rate, non-invasive blood pressure, oxygen saturation and electrocardiogram till completion of surgery. Spinal anaesthesia was given at the L3-L4 space with hyperbaric bupivacaine in sitting position and was immediately made to lie in supine position. Study drugs were administered to the study patients one minute after the spinal anaesthesia. Recording of the
MAP and HR was done at baseline and in the successive time following the administration of drugs. Systolic blood pressure of more than $60 \mathrm{~mm}$ of $\mathrm{Hg}$ was categorized under the definition of significant hypotension and if it occurred, the treatment was done with mephentermine. In cases in which more than $30 \mathrm{mg}$ of inj. Mephentermine was required, inj. Phenylepherine was administered in the form a rescue drug. Presence of HR of less than 50 beats per minute was categorized as bradycardia and was treated by atropine. In case of patients affected by tachycardia (HR of more than 140 beats per minute), bolus IV esmolol was given as the line of treatment. Recording of the various parameters such as amount of vasopressor needed (phenlyephrine), after 15 minutes of spinal anaesthesia, sensory level reached presence of intra-operative angina and intra/postoperative confusion and other side effects till six hours post-surgically was done.

All the results were analyzed by SPSS software. Chi-square test, Mann Whiteney $U$ test and one way ANOVA was used for the assessment of level of significance. P-value of less than 0.05 was considered to be significant.

\section{RESULTS}

Graph 1 highlights the demographic details of the patients. Mean age of the patients in the group 1, 2 and 3 were 69.5, 67.2 and 68.7 years respectively. Mean weight of the patients in the three study groups were $61.5,60.8$ and $58.9 \mathrm{~kg}$ respectively. Mean HR of the patients was $74.8,72.5$ and 71.4 beats per minute in the three study groups respectively. MAP at the baseline time in the three study groups was found to be $98.5,91.5$ and 93.7 respectively. Graph 2 and Graph 3 shows the Mean HR and MAP at baseline and various time intervals. 14 patients in the group 3 were observed to have bradycardia while none of the patients in group 1 and 1 patient in group 2 suffered from bradycardia at baseline. Significant results were obtained while comparing the mephentemine used and amount of patients affected by bradycardia when compared in between the various study groups ( $p$-value $<0.05$, Table 2).

\section{Graph 1: Demographic details of the patients}

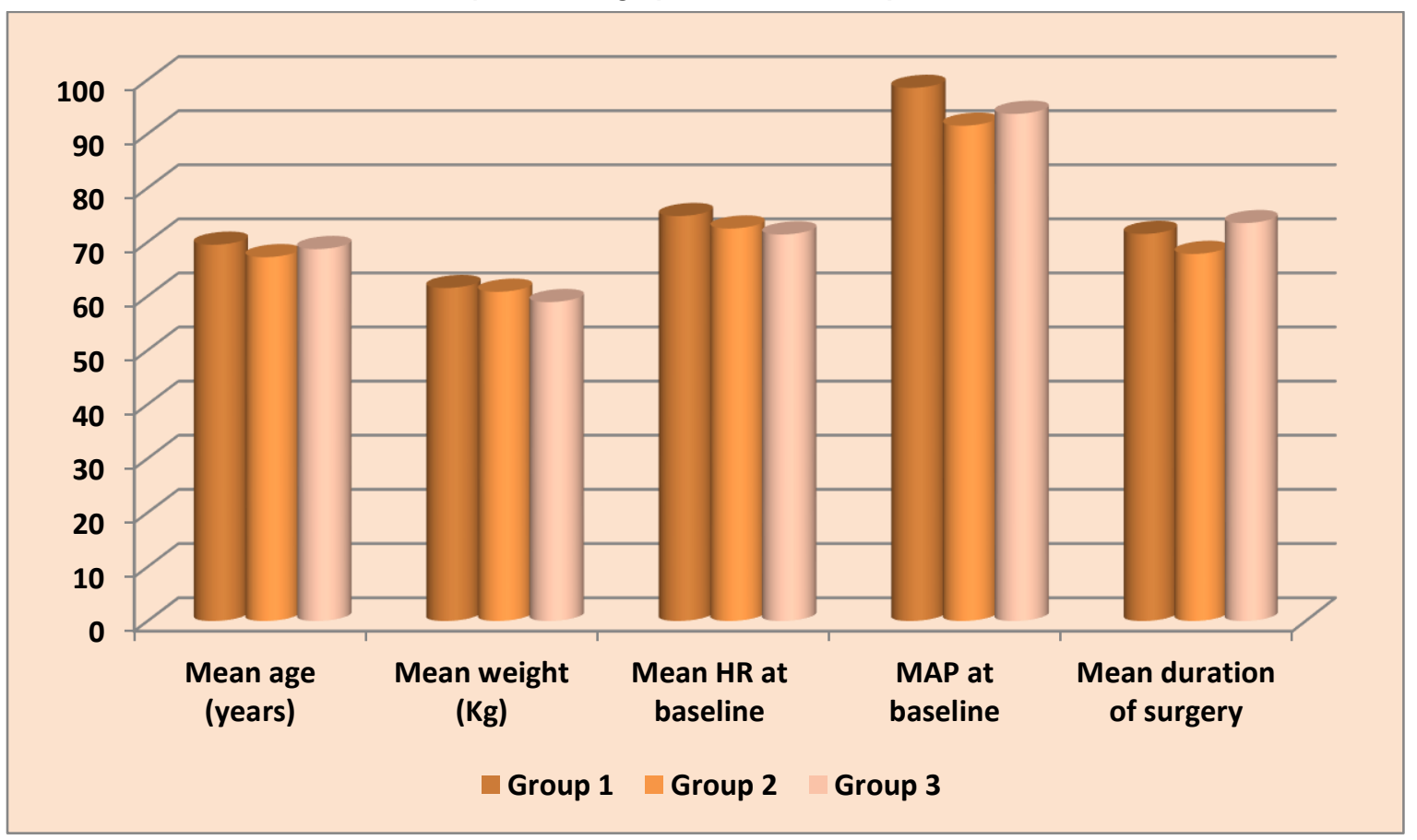


Sanjay Jain \& Atul Kaushik. Atropine with Ephedrine in Prevention of Hypotension Induced by Spinal Anaesthesia

Table 1: P-value for the comparison of demographic details

\begin{tabular}{lcccc}
\hline Parameter & Group 1 & Group 2 & Group 3 & p-value \\
\hline Mean age (years) & 69.5 & 67.2 & 68.7 & 0.52 \\
Mean weight (Kg) & 61.5 & 60.8 & 58.9 & 0.42 \\
Mean HR at baseline & 74.8 & 72.5 & 71.4 & 0.58 \\
MAP at baseline & 98.5 & 91.5 & 93.7 & 0.35 \\
Mean duration of surgery & 71.5 & 67.8 & 73.5 & 0.41 \\
\hline
\end{tabular}

Graph 2: Mean HR at baseline and various time intervals

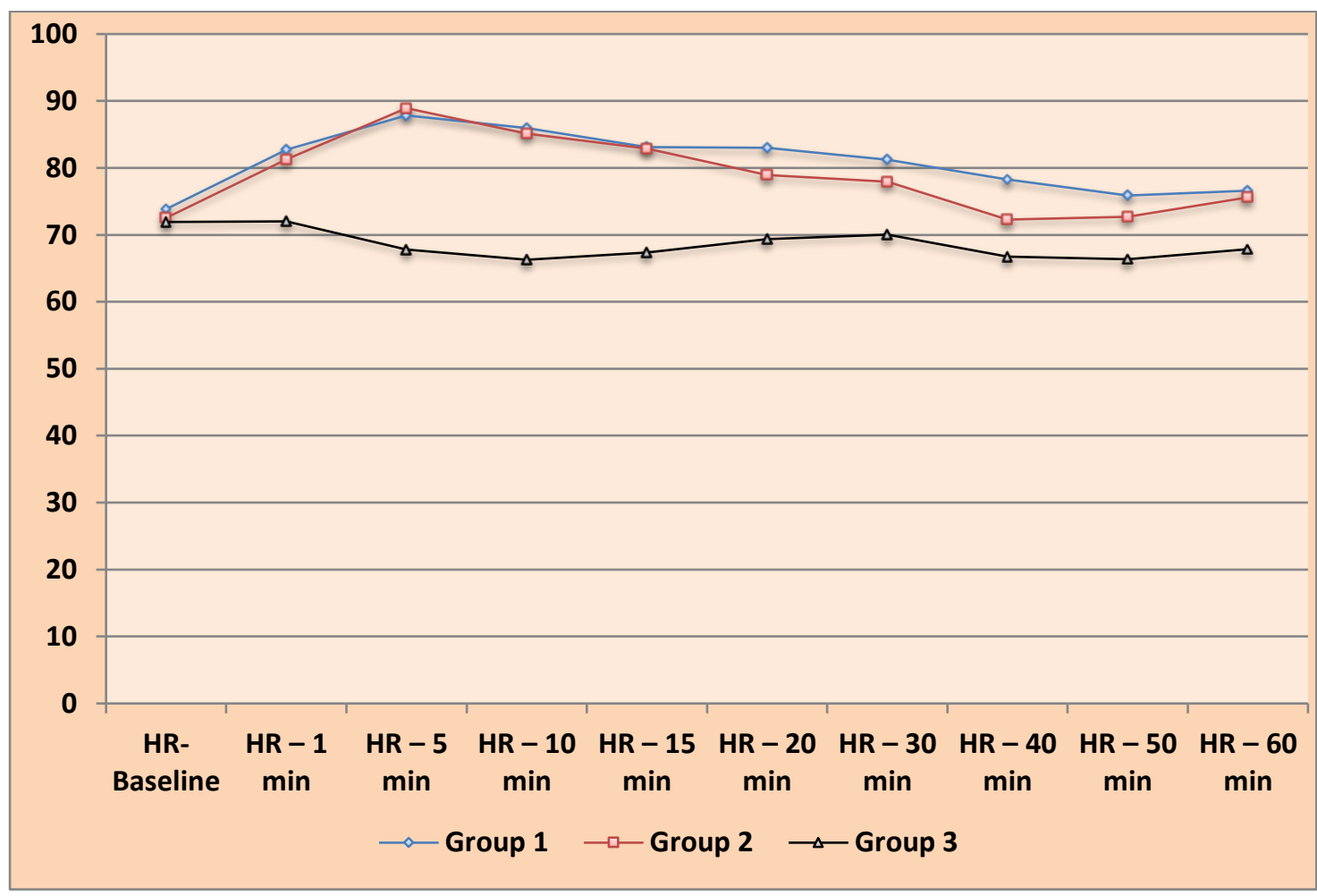

Graph 3: MAP at baseline and various time intervals

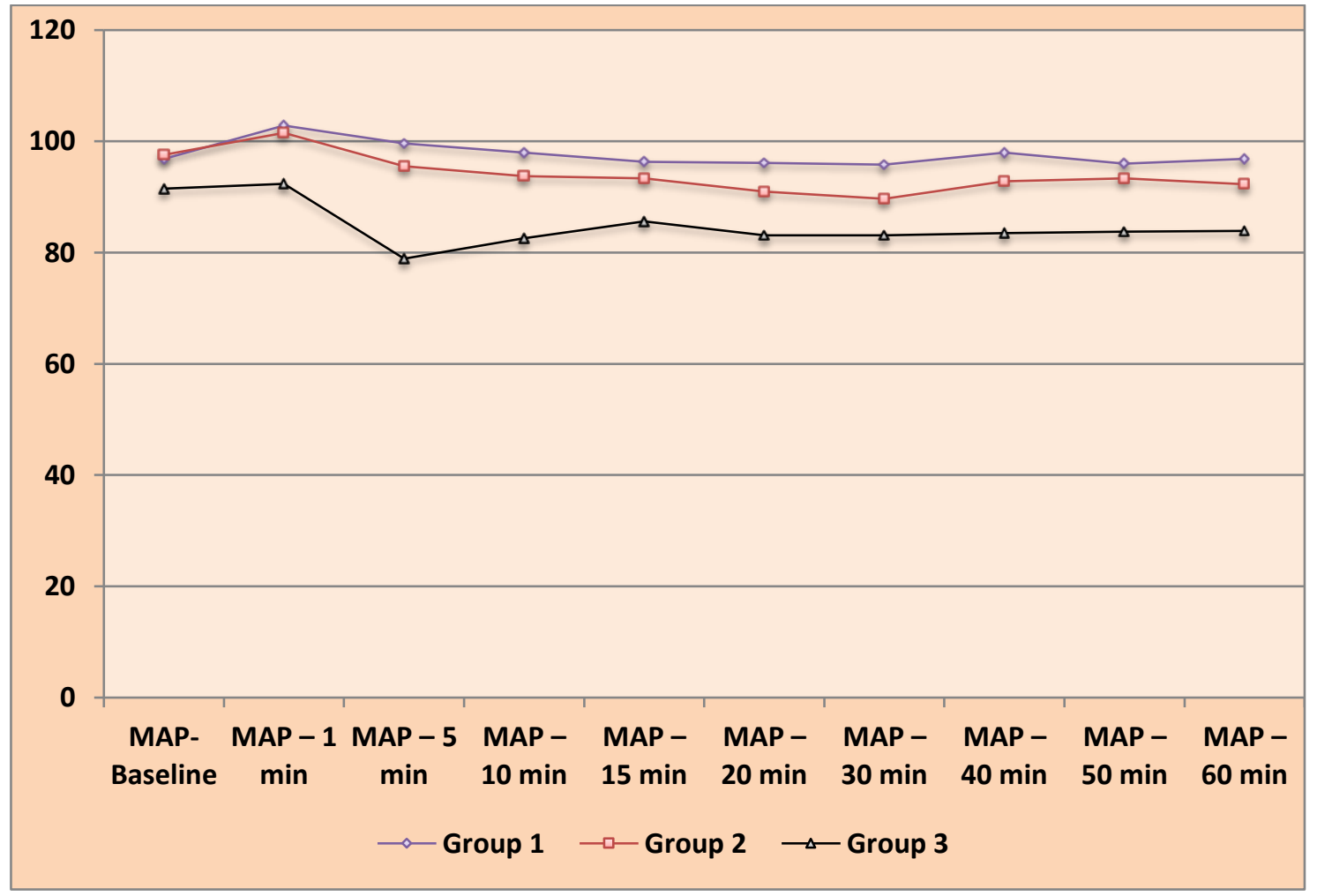


Table 2: $p$-value for comparison of MAP at baseline

\begin{tabular}{lcccc}
\hline Parameter & \multicolumn{4}{c}{ No. of patients } \\
\cline { 2 - 5 } Mephentemine used & Group 1 & Group 2 & Group 3 & p-value \\
Bradycardia & 3 & 2 & 21 & $0.02^{*}$ \\
Tachycardia & 0 & 1 & 14 & $0.03^{*}$ \\
Other adverse effects & 2 & 0 & 0 & 0.52 \\
\hline
\end{tabular}

*Significant

\section{DISCUSSION}

Hypotension and bradycardia are the common adverse effects associated spinal anaesthesia. Hypotension is risk factor at age of 40 years or older and its subarachnoid puncture level above the L3-L4, its sympathetic block height T5 or higher, and baseline systolic blood pressure less than $120 \mathrm{mmHg}$. By use of $\beta$ adrenergic blockers, prolonged PR interval on electrocardiogram, ASAPS I and block height T5 or higher, these factor reduce the risk factor for development of bradycardia include heart rate less than 60 beats per minute. Now days various techniques are advocated for the prevention of hypotension and bradycardia which include pre or co-loading of IV fluid, vasopressors, and physical methods such as table tilt, leg binders, and compression devices. ${ }^{7,8}$ Hence, we carried this study to evaluate and compare the heart rate and mean arterial pressure after spinal anaesthesia with prophylactic use of atropine, ephedrine and placebo in elderly patients.

In the present study, the incidence of bradycardia was significantly higher at different time intervals in the placebo group in comparison with the other study groups. Also, treatment was required to treat this bradycardia in the placebo group ( $p$-value < 0.05). Persistence of lower heart rate was observed in the placebo group in the present study even at the middle of the surgery. For the treatment of hypotension, mephentermine was required in more than 50 percent, 5 percent and 5 percent of the patients of the placebo group, ephedrine group and the atropine group respectively. When compared to ephedrine or atropine group, in patients of placebo group, mephentermine was significantly used ( $p$-value < 0.05). However, non-significant results were obtained while comparing the ephedrine with atropine group in regard to mephentermine use. When compared to the other study groups, lower values of MAP were observed in placebo group at most of the time intervals. However, in comparison with the atropine group, significantly lower values of MAP at baseline were observed in the ephedrine group. Attenuation of spinal induced spinal hypotension can occur due to administration of ondansetron. Marashi SM et $\mathrm{al}^{9}$ evaluated the impact of administration of ondansetron through intravenous route and concluded that spinal induced hypotension, bradycardia and shivering are significantly attenuated by administration of two different doses of intravenous ondansetron in comparison to the control saline group. However, the hemodynamic profiles and shivering in experimental groups were not statistically different. Owczuk $\mathrm{R}$ et al ${ }^{10}$ verified the hypothesis that blockade of type 3 serotonin receptors by intravenous ondansetron administration might reduce hypotension and bradycardia induced by spinal anaesthesia. Patients of the first group received $8 \mathrm{mg}$ i.v. ondansetron while the patients of the other group received isotonic $\mathrm{NaCl}$ solution and they concluded that fall of systolic and mean blood pressure is attenuated by ondansetron when given intravenously, but does not have an influence on diastolic blood pressure or heart rate. Brooker RF et al ${ }^{11}$ conducted a randomized clinical trial to compare phenylephrine and epinephrine and revealed that an increase in heart rate and cardiac output occurs by the epinephrine management of tetracaine spinal-induced hypotension. Phenylephrine management of tetracaine spinal-induced hypotension decreases heart rate and cardiac output while restoring systolic, mean, and diastolic blood pressure. Sahoo $\mathrm{T}$ et al ${ }^{12}$ evaluated the effect of ondansetron, as a 5-HT3 receptor antagonist, on the haemodynamic response following subarachnoid block in parturients undergoing elective caesarean section and observed a reduction in the hypotension occurs when Ondansetron is given intravenously $5 \mathrm{~min}$ before subarachnoid block. Kelsaka et al ${ }^{13}$ evaluated and compared the efficacy of ondansetron and meperidine in the prevention of shivering during and after spinal anesthesia and found that ondansetron and meperidine have similar anti-shivering effects.

\section{CONCLUSION}

From the above results, the present study concludes that in elderly patients, profile of atropine is better than ephedrine in the maintenance of hemodynamic in elderly patient. However; future studies are recommended.

\section{REFERENCES}

1. Auroy $Y$, Narchi P, Messiah A, Litt L, Rouvier B, et al. Serious complications related to regional anesthesia: results of a prospective survey in France. Anesthesiology 1997;87: 479-486. 2. Lim HH, Ho KM, Choi WY, Teoh GS and Chiu KY. The use of intravenous atropine after a saline infusion in the prevention of spinal anesthesia-induced hypotension in elderly patients. Anesth Analg 2000; 91:1203-6

3. Arndt JO, Bomer W, Krauth J and Marquardt B. Incidence and time course of cardiovascular side effects during spinal anesthesia after prophylactic administration of intravenous fluids or vasoconstrictors. Anesth Analg 1998; 87:347-54.

4. Dobson PM, Caldicott LD, Gerrish SP, Cole JR and Channer KS. Changes in haemodynamic variables during transurethral resection of the prostate: comparison of general and spinal anaesthesia. Br J Anaesth 1994; 72:267-71

5. Eroglu F, Yavuz L, Ceylan BG, Sevin G, Soyupek S Prophylactic effects of systemic oral ephedrine in spinal anesthesia-induced hypotension during transurethral prostatectomy. Scand J Urol Nephrol 2003;37: 145-150. 
6. Sternlo JE, Rettrup A, Sandin R. Prophylactic i.m. ephedrine in bupivacaine spinal anaesthesia. Br J Anaesth 1995; 74: 517-520.

7. PUN Nze Effect of Pre-medication with Atropine on the Blood Pressure of Parturient Undergoing Caesarian Section under Spinal Anaesthesia. Orient Journal of Medicine 2003; 15: 1-4.

8. Hirabayashi Y, Saitoh K, Fukuda H, Shimizu R Atropine has little significance as a premedication for spinal anesthesia]. Masui 1994; 43: 306-310.

9. Marashi SM, Soltani-Omid S, Soltani Mohammadi S, Aghajani Y, Movafegh A. Comparing Two Different Doses of Intravenous Ondansetron With Placebo on Attenuation of Spinal-induced Hypotension and Shivering. Anesth Pain Med 2014 18;4(2):12055.

10. Owczuk R, Wenski W, Polak-Krzeminska A, Twardowski P, Arszułowicz R, Dylczyk-Sommer A, Wujtewicz MA, Sawicka W, Morzuch E, Smietanski M, Wujtewicz M. Ondansetron given intravenously attenuates arterial blood pressure drop due to spinal anesthesia: a double-blind, placebo-controlled study. Reg Anesth Pain Med 2008;33(4):332-9.

11. Brooker RF, Butterworth JF, Kitzman DW, Berman JM, Kashtan HI, McKinley AC. Treatment of hypotension after hyperbaric tetracaine spinal anesthesia. A randomized, doubleblind, cross-over comparison of phenylephrine and epinephrine. Anesthesiology 1997;86(4):797-805.
12. Sahoo T, SenDasgupta C, Goswami A, Hazra A. Reduction in spinal-induced hypotension with ondansetron in parturients undergoing caesarean section: a double-blind randomised, placebo-controlled study. Int J Obstet Anesth 2012;21(1):24-8.

13. Kelsaka E, Baris S, Karakaya D, Sarihasan B. Comparison of ondansetron and meperidine for prevention of shivering in patients undergoing spinal anesthesia. Reg Anesth Pain Med 2006;31(1):40-5.

\section{Source of Support: Nil. Conflict of Interest: None Declared.}

Copyright: (c) the author(s) and publisher. IJMRP is an official publication of Ibn Sina Academy of Medieval Medicine \& Sciences, registered in 2001 under Indian Trusts Act, 1882.

This is an open access article distributed under the terms of the Creative Commons Attribution Non-commercial License, which permits unrestricted non-commercial use, distribution, and reproduction in any medium, provided the original work is properly cited.

Cite this article as: Sanjay Jain, Atul Kaushik. Assessment of Prophylactic Effect of Atropine with Ephedrine in Prevention of Hypotension Induced by Spinal Anaesthesia in Elderly Patients: A Comparative Study. Int J Med Res Prof. 2016; 2(4):174-78. 